\title{
Articles
}

\section{The Role of Depth versus Breadth of Vocabulary Knowledge in Success and Ease in L2 Lexical Inferencing}

\author{
Sarvenaz Hatami and Mansoor Tavakoli
}

This study determines whether breadth and depth of vocabulary knowledge are related to $L 2$ ease and success in lexical inferencing. To this end, two tests measuring vocabulary breadth and depth were administered to 50 participants. Two weeks later, all participants received an inferencing task and rated the degree of perceived ease in inferencing on a 6-point Likert-scale questionnaire. The findings indicated that although both vocabulary breadth and depth played an important role in lexical inferencing success, vocabulary breadth made a more important contribution. The results further revealed that neither vocabulary breadth nor depth had a significant effect on perceived ease of inferencing.

Cette étude détermine dans quelle mesure l'étendue et la profondeur des connaissances lexicales sont liées à la facilité en L2 et à la réussite en inférence linguistique. À cette fin, nous avons fait passer à cinquante participants deux examens pour évaluer l'étendue et la profondeur de leurs connaissances lexicales. Deux semaines plus tard, nous avons donné à tous les participants une tâche d'inférence et en avons évalué le degré de facilité perçue avec un questionnaire en 6 points sur l'échelle Likert. Les résultats indiquent que si l'étendue et la profondeur des connaissances lexicales jouent tous les deux un rôle important dans la réussite en inférence lexicale, l'étendue du vocabulaire y contribuent davantage. L'étude a également démontré que ni l'étendue ni la profondeur des connaissances lexicales n'ont un effet significatif sur la facilité d'inférence perçue.

Language-learners, teachers, and researchers agree that vocabulary is an essential element in the process of learning a language (Schmitt, 2008), because words are the primary conveyors of meaning (Vermeer, 2001) and thus carry the main information load in communication. As Wilkins (1972) states, "without grammar very little can be conveyed, without vocabulary nothing can be conveyed" (p. 111). Considering the centrality of vocabulary knowledge and its development, it is necessary for second-language (L2) learners who wish to operate at a high level in English to learn many thousands of word families. Previously it was shown that a learner needed to know over 3,000 word families or about 5,000 individual word forms in order to achieve a 
95\% coverage of words in academic texts, which was regarded as a threshold for minimum comprehension (Laufer, 1997). More recent research indicates that learners must know $98-99 \%$ of words in a written text for sufficient comprehension (Hu \& Nation, 2000), which means that they need to know 8,000-9,000 word families to be able to read a variety of texts in English (Nation, 2006).

However, not all learners achieve such targets, and as a result, they often face situations where they cannot fully comprehend language input because they do not know the meaning of all the words that they encounter. In such cases, learners use certain strategies to compensate for their insufficient L2 lexical knowledge. The primary strategy that learners use when they attempt to identify the meanings of unknown words is lexical inferencing, which "involves making informed guesses as to the meaning of a word in light of all available linguistic cues in combinations with the learner's general knowledge of the world, her awareness of context and her relevant linguistic knowledge" (Haastrup, 1991, p. 40). Paribakht and Wesche (1999) found that their university English-as-a-second language (ESL) students used inferencing in about $78 \%$ of all cases where they actively tried to identify the meanings of unknown words. Lexical inferencing, therefore, is an important process in both listening and reading comprehension. In fact, lexical inferencing appears to be closely linked to incidental word-learning through reading, and thus it is also of great importance in the process of vocabulary development (Haastrup, 1989, 1991; Schouten-van Parreren, 1989).

Because of the great importance of lexical inferencing in the process of learning a language, many studies have examined factors that can influence inferencing behavior. These can be divided into contextual factors and reader-based factors. Contextual factors include the importance of the unknown word to comprehension of the text (Brown, 1993); the characteristics of the word and the text containing the word, as well as the nature of the comprehension task (Fraser, 1999; Paribakht \& Wesche, 1999); the length of the text (Haynes, 1993); the availability of clear contextual cues (Dubin \& Olshtain, 1993); and the semantic richness of the context (Li, 1988). Learner-related or reader-based factors include the learner's previous L2 learning experience (Paribakht \& Wesche); the learner's degree of attention to the details in the text (Frantzen, 2003; Nassaji, 2003), and as his or her preconceptions about the possible meaning of the word (Frantzen); the size of the learner's receptive vocabulary knowledge (Laufer, 1997), depth of vocabulary knowledge (Nassaji, 2004; Qian, 1998, 2005), procedural knowledge (Ellis, 1994), sight vocabulary and background knowledge of the passage or familiarity with the topic (Pulido, 2007); the learner's ability to make use of extratextual cues (Haastrup, 1991); the level of mental effort involved in the task (Fraser); and the effect of the learner's native language on the process (Paribakht, 2005). Moreover, learners' L2 proficiency has been shown to mediate 
attempts at lexical inferencing (Bengeleil \& Paribakht, 2004; Chern, 1993; Fraser; Haastrup, 1991; Haynes, 1993; Ittzes, 1991; Morrison, 1996).

Studies on lexical inferencing have also been conducted to identify and classify the knowledge sources and contextual clues used by first-language (L1) and L2 readers in processing unknown words (Ames, 1966; Carton, 1971; Haastrup, 1991; Paribakht \& Wesche, 1999). One of these knowledge sources has been found to be vocabulary knowledge. In order to define knowledge of a lexical item, in recent decades, various but generally complementary frameworks have been developed (Nation, 2001; Qian, 1998, 1999; Read, 1993; Wesche \& Paribakht, 1996). In all these frameworks, researchers no longer regard vocabulary knowledge as a single dimension, but as a multidimensional construct. A distinction has often been made between two dimensions of vocabulary knowledge: depth and breadth (or size). Breadth of vocabulary knowledge is defined as vocabulary size, or the number of words for which a learner has at least some minimum knowledge of meaning (Nation, 2001). Various types of assessment tools with varied formats have been used to measure this dimension of vocabulary knowledge, including tests that require the learner to identify a synonym or definition for a particular word, to translate a word into L1, or to use checklists (Wesche \& Paribakht). Such vocabulary measures require "just a single response to each target word and, by implication, give only a superficial indication of whether the word is known or not" (Read, 2004, p. 211). Depth of vocabulary knowledge, on the other hand, is defined as a learner's level of knowledge of various aspects of a given word, or how well he or she knows this word (Read, 1993). The depth dimension refers to various levels of knowledge (Wesche \& Paribakht) and is also associated with various kinds of knowledge such as knowledge of pronunciation, spelling, meaning, register, and frequency, as well as morphological, syntactic, and collocational properties (Qian).

Related research reveals a possible strong link between depth and breadth of vocabulary knowledge (Nurweni \& Read, 1999). Qian (1999) states, "breadth and depth are two interconnected dimensions of vocabulary knowledge, the development of which are interdependent to a substantial extent" (p. 287). Therefore, in assessing the relationship between vocabulary knowledge and lexical inferencing, both depth and breadth of vocabulary knowledge should be given equal attention. However, although breadth and depth are related constructs and the parallel development of the two has been advocated by many researchers (Read, 2004; Vermeer, 2001), according to Laufer et al. (2004), "for diagnostic purposes we need separate estimates of both size and strength to fully understand the degree of a learner's vocabulary knowledge" (p. 224).

Some researchers have attempted to discover the relationship between vocabulary knowledge and L2 lexical inferencing behavior (Ittzes, 1991; Laufer, 1997; Nassaji, 2004; Pulido, 2007). Pulido examined the effects of topic 
familiarity and passage sight vocabulary (i.e., vocabulary knowledge specific to a given text) on success and ease in L2 lexical inferencing. The results consistently demonstrated that as passage sight vocabulary increased, so did the ability to make correct inferences. It was further revealed that for those with stronger passage sight vocabularies, the role of passage sight vocabulary in the perception of ease in lexical inferencing depended on the degree of familiarity with the topic. However, for those with weaker passage sight vocabularies, equivalent degrees of difficulty in inferencing were perceived regardless of the degree of familiarity with the topic. In another study that examined the relationship between ESL learners' depth of vocabulary knowledge and their use and success of lexical inferencing strategy, Nassaji (2004) found that depth of vocabulary knowledge made a significant contribution to inferential success over and above the contribution made by the learner's degree of strategy use.

Moreover, the research indicates that vocabulary knowledge is one of the best predictors of learners' ability in reading comprehension (Nation, 2001; Qian, 1998, 1999; Read, 2000; Sternberg, 1987). Qian, for example, demonstrated that scores on vocabulary size, depth of vocabulary knowledge, and reading comprehension were highly correlated. Furthermore, he found that depth of vocabulary knowledge was not only a better predictor of $\mathrm{L} 2$ reading comprehension, but that it also made a unique contribution to L2 reading comprehension over and above the contribution made by size of vocabulary knowledge.

Expanding on this line of research, in this study we investigated whether size and depth of vocabulary knowledge differentially affected L2 inferential success during reading. Considering the high correlations between lexical inferencing success and vocabulary knowledge, reading comprehension, vocabulary development, and consequently second-language acquisition (Haastrup, 1989, 1991; Hafner, 1967; Nassaji, 2004; Pulido, 2007; Schoutenvan Parreren, 1989), research aimed at examining factors that would make the process of L2 lexical inferencing easier and more successful could be of great significance and a fundamental topic in SLA research.

\section{The Present Study}

\section{Research Questions}

This study sought answers to the following questions.

1. Do EFL learners with different scores on breadth of vocabulary knowledge differ in terms of (a) success in L2 lexical inferencing, and (b) perceived ease in L2 lexical inferencing?

2. Do EFL learners with different scores on depth of vocabulary knowledge differ in terms of (a) success in L2 lexical inferencing, and (b) perceived ease in L2 lexical inferencing? 
3. Do depth and breadth of vocabulary knowledge differ in their contribution to L2 lexical inferencing success?

4. 'Is there a relationship between success and perceived ease in L2 lexical inferencing?

\section{Method}

\section{Participants}

The population from which the participants were selected for this study included 64 senior students aged 21-30 majoring in English translation at the University of Isfahan, Iran. Fourteen students were excluded from further data analysis because they did not complete all the required tasks, so data from only 50 participants ( 8 men, 42 women) were retained. The participants' L1 background (i.e., Persian) remained constant, which neutralized its effects on the outcome of the study.

\section{Instruments}

Vocabulary Levels Test (VLT). This is a test of receptive knowledge of English vocabulary used to measure the size of learners' vocabulary knowledge. It was originally developed by Nation (1983) and updated and validated by Schmitt, Schmitt, and Clapham (2001). The VLT is the closest we have to a standard vocabulary test and is accepted by a number of L2 researchers as an appropriate measure of vocabulary size (Laufer \& Paribakht, 1998). In this study, we used version 1 of this test, which was updated by Schmitt (2000). This version is composed of five parts that represent five levels of vocabulary size, that is, the 2,000-word-family level, the 3,000-word-family level, the 5,000-word-family level, the Academic Word List level, and the 10,000-wordfamily level. The reliability indices (Cronbach's alpha) for all five sections are high (i.e., $0.92,0.92,0.92,0.95$, and 0.91 , respectively) as reported by Schmitt et al. (2001).

Each level has 10 test items, each consisting of six words on the left and three definitions on the right. Candidates are required to match the three definitions with three of the six words on the left. A sample test item is provided below.

1 business

2 clock

3 horse $\quad \ldots 6 \ldots$ part of a house

4 pencil $\quad \ldots 3 \ldots$ animal with four legs

5 shoe $\quad \ldots 4 \ldots$ something used for writing

6 wall

In scoring, each word correctly chosen is worth one point. The maximum possible score is 150 for the five levels, each of which consists of 30 items. 


\begin{tabular}{|ll|ll|}
\hline$\square$ beautiful & $\square$ quick & $\square$ change & $\square$ doctor \\
$\square$ surprising & $\square$ thirsty & $\square$ noise & $\square$ school \\
\hline
\end{tabular}

Word-Associates Test (WAT). This is a test developed by Read (1993) for measuring learners' depth of vocabulary knowledge in English. We used a more recent version of the WAT in this study and we found it to be reliable, with a coefficient of 0.93 (Read, 1998). This version consists of 40 items, each comprising a target word followed by a list of eight words, four of which are related to the target word whereas the other four are not. The test-taker is required to identify the four words related to the target word, so each item has four correct choices. A sample test item is provided above.

In the left box, one to three words (out of four) are synonyms of either the whole meaning of the target word (in this item, sudden) or a component of its meaning; and in the right box, one to three words are collocates of the target word, often occurring together with the target word in a sentence. In this example, the correct answers on the left side are quick and surprising, and the correct answers on the right side are change and noise. So this version of WAT is designed to measure two aspects of the depth of vocabulary knowledge: meaning and collocation.

In scoring, one point is awarded for each correctly chosen word. The maximum possible score is 160 as there are 40 items with four correct responses for each. Further details about the test can be found in Read $(1993,1998,2000)$.

Text and Target Words. A single passage (approximately 440 words) on the origin of man, published in a monthly general-interest family magazine (Reader's Digest, October 1995, Australian edition) was selected, modified (shortened), and then used to elicit the participants' inferencing success. It was given to a number of TEFL postgraduate students to verify its suitability and content validity. Ten lexical items were chosen in the passage as target words (TWs). Only content words were selected as TWs, that is, four nouns, two verbs, and four adjectives. To ensure that nobody had prior knowledge of the TWs, students were presented with the same passage two weeks before carrying out the lexical inferencing task and were asked to read it and circle all the words they did not know. Ten words identified as unfamiliar by all the students were chosen as TWs for the inferencing task. All TWs were in boldface type and underlined (see Appendix for the passage "How Man Began"). To measure lexical inferencing, participants were asked to guess and write the meaning of each TW in the language of their choice (i.e., Persian, English, or both).

Likert-Scale Questionnaire. A six-point scale modeled after Pulido (2007) was used to determine the degree ease perceived by the learners in infer- 
ring the meanings of the TWs. They were asked to mark on the scale their self-perceived level of ease in guessing the meaning of each target word $(1=$ very difficult; $2=$ difficult $3=$ moderately difficult $;=$ moderately easy; $5=$ easy; $6=$ very easy).

\section{Procedures}

Data were collected in two sessions. During Session 1, the two tests measuring breadth and depth of vocabulary knowledge, that is, the Vocabulary Levels Test and the Word-Associates Test, were administered consecutively (with a short break in between) to all participants. Before taking the tests, we explained the general purpose of the study to the students. They were also given detailed instructions on how to take the tests and were assured of the confidentiality of results. In the same session and after taking the two vocabulary tests, we presented the students with the same passage as was used in the lexical inferencing task and asked them to read it and circle all the words they did not know. The 10 words identified as unfamiliar by all students were chosen as TWs for the inferencing task. This was to ensure that no one had prior knowledge of the TWs. The first session lasted almost 90 minutes.

We conducted Session 2 two weeks later, when all participants were given the reading and inferencing task, that is, the passage consisting of 10 unfamiliar TWs underlined and in boldface type. Participants were asked to read the text quickly for general comprehension and then to read it again and try to guess the meanings of the unfamiliar TWs in the language of their choice; if they could not think of an exact meaning or translation, they were asked to give an approximate one. Immediately after inferring the meaning of each TW, participants were asked to rate their degree of perceived ease in inferring the meaning of each TW on the Likert-scale questionnaire. Session 2 lasted approximately 60 minutes.

\section{Results}

Relationship between Breadth of Vocabulary Knowledge and Success in L2 Lexical Inferencing

To determine the relationship between breadth of vocabulary knowledge and L2 lexical inferencing success, we took a number of steps. In the first, following Nassaji (2004), the degree of success in lexical inferencing was determined using a three-point scale representing unsuccessful, partly successful, and successful inferences. Participants' inferred meanings for the unfamiliar targets words were evaluated as successful if they were semantically and syntactically appropriate. Inferences were evaluated as partly successful if they were semantically appropriate but syntactically deviant (e.g., if a verb instead of a noun was given). An attempt was regarded as unsuccessful when an inference met none of the conditions above or when no meaning was inferred. 
Lexical inferencing was scored as follows: $0=$ unsuccessful; $0.5=$ partly successful; $1=$ successful. All responses were scored by two independent raters, the researcher and a university professor in the field of TEFL. The mean score for the full sample $(n=50)$ for success in L2 lexical inferencing was 4.2 $(S D=2.29$, Range: $1-10)$ out of a maximum possible score of 10 .

For the second step in the analysis, we divided the participants into two groups according to their scores on the breadth of vocabulary knowledge test (VLT). Because the participants were all advanced learners of EFL, most had mastery of the first four levels of the VLT, and so in order to divide them into two groups, we considered their scores on the 10,000 word-family level. First, a cut-off point had to be determined. Based on Read's (1988) mastery criterion of 16 out of 18 on an earlier version of the test, Schmitt et al. (2001) chose 26 out of 30 to indicate mastery of a given level. In our study, choosing 26 or 25 (out of 30) as cut-off points would have divided the learners into two extremely disparate groups; therefore, for the purposes of this research, we decided on 24 out of 30 as a reasonable cut-off point. This means that an estimated $80 \%$ of the words at this level have been mastered. Learners who scored at or above 24 on the 10,000 word-family level were classified as Group 1B(readth), and those who obtained scores below 24 were classified as Group 2B. Table 1 summarizes the means, standard deviations, and obtained score ranges on the VLT for Groups 1B and 2B. There were 12 students in Group 1B, and 38 students in Group 2B.

As a final step, an independent-samples t-test was conducted to compare the lexical inferencing scores of the two groups, 1B (with larger size of vocabulary) and 2B (with smaller size of vocabulary). The results showed that scores in lexical inferencing success varied significantly across the two groups $(t[48]=-4.19, p<0.001$, see Table 2$)$.

The overall mean of lexical inferencing success for Group $1 \mathrm{~B}$ is significantly higher than that for Group 2B, indicating that EFL learners with varied scores on breadth of vocabulary knowledge differ in terms of success in L2 lexical inferencing.

Table 1

Vocabulary Levels Test (VLT) Scores Groups 1B and 2B

\begin{tabular}{lccccc}
\hline Group & $\begin{array}{c}\text { Mean } \\
(\text { max. score }=150)\end{array}$ & SD & Variance & Min. & Max. \\
\hline 1B & 142.58 & 2.67 & 7.17 & 138 & 147 \\
2B & 121.1 & 11.89 & 141.5 & 94 & 135 \\
\hline Total & 126.26 & 13.94 & 194.32 & 94 & 147 \\
\hline
\end{tabular}


Table 2

Lexical Inferencing Success Sores: Groups 1B, 2B (based on breadth of vocabulary knowledge)

\begin{tabular}{|c|c|c|c|c|c|c|c|}
\hline Variable & Group* & $N$ & $\begin{array}{c}\text { Lower } \\
C L^{*} \\
\text { Mean }\end{array}$ & $\begin{array}{l}\text { Mean } \\
(\max . \\
=10)\end{array}$ & $\begin{array}{c}\text { Upper } \\
C L^{*} \\
\text { Mean }\end{array}$ & $\begin{array}{l}\text { Standard } \\
\text { Deviation }\end{array}$ & $\begin{array}{c}\text { Standard } \\
\text { Error }\end{array}$ \\
\hline Success & $2 \mathrm{~B}$ & 38 & 2.89 & 3.54 & 4.18 & 1.97 & 0.31 \\
\hline Success & $1 \mathrm{~B}$ & 12 & 5.00 & 6.29 & 7.58 & 2.03 & 0.58 \\
\hline Difference (2B-1B) & & & -4.07 & -2.75 & -1.43 & 1.98 & 0.65 \\
\hline
\end{tabular}

* Confidence level

Relationship Between Breadth of Vocabulary Knowledge and Perceived Ease of L2 Lexical Inferencing

The next stage of analysis examined the relationship between breadth of vocabulary knowledge and perceived ease of L2 lexical inferencing. To this end, participants were divided into the same two groups as before on the basis of their scores on the breadth of vocabulary knowledge test (VLT). Again, learners who scored at or above 24 (out of 30) on the 10,000-word-family level were classified as Group 1B(readth), and those who obtained scores below 24 on the 10,000-word-family level were classified as Group 2B (for a summary of these two groups' performance on the VLT, see Table 1).

The next step was to determine whether there was any significant difference between Groups 1B and 2B regarding their perceived ease in L2 lexical inferencing. As stated above, participants rated their perceived ease of inferencing immediately after guessing the meaning of each unfamiliar TW on a six-point scale. A Mann-Whitney U-test was conducted on the perceived ease of inferencing as marked on the scales for the two groups of $1 \mathrm{~B}$ and $2 \mathrm{~B}$. No significant difference was found between Groups $1 \mathrm{~B}$ and $2 \mathrm{~B}$ as to their perceived ease while inferring the meanings of unfamiliar words (the mean of ranks for Group 1B and Group 2B were 22.21 and 26.54, respectively; $U=188.5, Z=-0.904, p=0.36$ ).

Relationship Between Depth of Vocabulary Knowledge and Success in L2 Lexical Inferencing

To determine the relationship between depth of vocabulary knowledge and L2 lexical inferencing success, we first divided the participants into two groups on the basis of their scores on the depth of vocabulary knowledge test (WAT). Participants were divided into two groups based on their percentile rank for the scores they had obtained on the WAT. Percentile ranks are often used when comparing a candidate's score with that of others. 
Table 3

Word-Associates Test (WAT) Scores Groups 1D and 2D

\begin{tabular}{lccccc}
\hline Group & $\begin{array}{c}\text { Mean } \\
(\max .=160)\end{array}$ & $S D$ & Variance & Min & Max \\
\hline 1D & 132.7 & 5.76 & 33.17 & 126 & 145 \\
$2 \mathrm{D}$ & 114.8 & 11.48 & 131.84 & 83 & 125 \\
Total & 128.4 & 12.82 & 164.45 & 83 & 145 \\
\hline
\end{tabular}

Learners whose scores fell at or above the 50th percentile were classified as Group 1D(epth), and those whose scores fell below the 50th percentile rank were classified as Group 2D. There were 24 students in Group 1D and 26 in Group 2D (the number of participants in the two groups was unequal because two participants in the middle had the same score). Table 3 summarizes the means, standard deviations, and obtained score ranges on the WAT for Groups 1D and 2D.

An independent-samples t-test conducted to compare the two groups' (1D and 2D) scores on lexical inferencing success showed that the scores obtained on the lexical inferencing task varied significantly across groups $(t[48]=-2.13, p<0.05$, see Table 4$)$.

The overall mean of lexical inferencing success for Group 1D is significantly higher than that for Group 2D, which indicates that these learners with varying scores on depth of vocabulary knowledge differ in terms of success in L2 lexical inferencing.

Relationship Between Depth of Vocabulary Knowledge and Perceived Ease of L2 Lexical Inferencing

In this stage of the analysis, we attempted to examine the relationship between depth of vocabulary knowledge and perceived ease of L2 lexical in-

Table 4

Lexical Inferencing Success Scores: Groups 1D, 2D (based on depth of vocabulary knowledge)

\begin{tabular}{lccccccc}
\hline Variable & Group & $N$ & $\begin{array}{c}\text { Lower CL } \\
\text { Mean }\end{array}$ & $\begin{array}{c}\text { Mean } \\
\text { (max. } \\
=10)\end{array}$ & $\begin{array}{c}\text { Upper CL } \\
\text { Mean }\end{array}$ & $\begin{array}{c}\text { Standard } \\
\text { Deviation }\end{array}$ & $\begin{array}{c}\text { Standard } \\
\text { Error }\end{array}$ \\
\hline Success & 2D & 26 & 2.75 & 3.56 & 4.35 & 1.97 & 0.38 \\
Success & 1D & 24 & 3.86 & 4.89 & 5.93 & 2.45 & 0.5 \\
Diff. (2D-1D) & & & -2.59 & -1.34 & -0.07 & 2.22 & 0.63 \\
\hline
\end{tabular}


ferencing. The participants were divided into two groups, one with higher scores on the WAT and the other with lower scores. We grouped them exactly as described above: learners whose scores fell at or above the 50th percentile were classified as Group 1D (epth), and those whose scores fell below the 50th percentile rank were classified as Group 2D (for a summary of each group's performance on the WAT, see Table 3 ).

The next step was to determine whether there was any significant difference between Groups 1D and 2D regarding their perceived ease in L2 lexical inferencing. A Mann-Whitney $U$ test was conducted on the perceived ease of inferencing ratings recorded by groups 1D and 2D. We found no significant difference between the groups regarding their perceived ease in inferring the meanings of unfamiliar words (the mean of ranks for Group 1D and Group 2D were 25.27 and 25.71, respectively, $U=306.5, Z=-0.11, p=-/ 914$ ).

\section{Contributions of Breadth versus Depth of Vocabulary Knowledge to} L2 Lexical Inferencing Success

To determine which dimension of vocabulary knowledge, depth or breadth, made a more important contribution to L2 lexical inferencing success, we carried out multiple regression analyses in which inferential success was used as the dependent variable, and depth and breadth of vocabulary knowledge were used as independent variables. Inferential success consisted of the learners' total score of success for the 10 TWs; breadth of vocabulary knowledge consisted of the learners' scores on the VLT; and depth of vocabulary knowledge consisted of the learners' scores on the WAT. Following Nassaji (2004), we performed forced-entry hierarchical multiple regressions in which each of the independent variables was entered into the regression model in varying orders. To determine the contribution of one of the independent variables over and above the contribution of the other, that variable was entered into the equation after the other. Any change in the magnitude of the $R^{2}$ was then considered the unique contribution of the second variable (Smith \& Glass, 1987).

Table 5 shows the results of the multiple regression analyses using breadth and depth of vocabulary knowledge as the independent variables and lexical inferencing success as the dependent variable. Section A presents the results of the regressions where breadth of vocabulary knowledge was first entered into the equation, followed by depth of vocabulary knowledge. Section B displays the results where breadth of vocabulary knowledge was entered after depth of vocabulary knowledge. In the column headed $R^{2}$ Change, the magnitude of the contribution of each variable at the point where that variable was entered into the regression analysis is indicated.

As Table 5 indicates, when entered on the first step, breadth of vocabulary knowledge explains a significant proportion of variance in lexical inferencing success $(37 \%, p<0.001)$. Entered on the second step, overall depth of vocab- 
Table 5

Multiple Regression Analyses

\begin{tabular}{lcccc}
\hline Predictor & Final $\beta$ & $R^{2}$ & $R^{2}$ Change & Sig. \\
\hline A: & & & & \\
1 - Breadth & 0.1 & 0.3704 & 0.3704 & $<0.0001$ \\
2 - Depth & 0.025 & 0.3774 & 0.0070 & 0.47 \\
\hline B: & & & & \\
1 - Depth & 0.097 & 0.2949 & 0.2949 & $<0.0001$ \\
2 - Breadth & 0.081 & 0.3774 & 0.0825 & 0.0162 \\
\hline
\end{tabular}

ulary knowledge accounted for only $0.7 \%$ of variance, which was not significant. In the next stage of analyses, when entered on the first step, depth of vocabulary knowledge accounted for $29 \%$ of the variance $(p<0.001)$ in inferential success. Entered on the second step, overall breadth of vocabulary knowledge accounted for an additional and significant proportion of variance in lexical inferencing success $(8 \%, p<0.05)$. The results suggest that among the two independent variables, learners' breadth of vocabulary knowledge is a stronger predictor of lexical inferencing success than depth of vocabulary knowledge.

\section{Relationship Between Success and Perceived Ease in L2 Lexical Inferencing}

The final stage of analysis was to examine whether perceived ease of L2 lexical inferencing and success in L2 lexical inferencing were correlated. To this end, a Spearman's rank order correlation was carried out between L2 inferential success and perceived ease for the full sample. Inferential success represented learners' total scores of success out of 10, and perceived ease of inferencing represented learners' total number of inferences perceived as easy. In order to determine the total number of inferences perceived as easy for each participant, the six-point scale was converted to a two-point scale consisting of only difficult and easy. This was done as follows: if the participants marked 1, 2, or 3 on the scale for a particular TW, it was regarded as difficult; if they marked 4,5 , or 6 on the scale, it was considered easy. The number of inferences perceived as easy was then calculated for each participant. The mean number of inferences perceived as easy for the full sample $(n=50)$ was 5.46 out of a maximum of $10(S D=2.54$; Range: $0-10)$.

The analysis revealed that success in L2 lexical inferencing and perceived ease of inferencing were moderately and positively correlated $(r=0.47$, 
$p<0.01)$. This could mean that the more successful the learners were in inferencing, the more ease they perceived while inferring the meanings of unfamiliar words.

\section{Discussion}

The findings of this study extend and confirm the research literature about the central role of vocabulary knowledge in L2 lexical inferencing and provide new insights into the nature of this process.

Analysis of the data revealed that EFL learners with greater vocabulary knowledge were more successful in L2 lexical inferencing than those with lesser vocabulary knowledge. Further analyses demonstrated that EFL learners with stronger depth of vocabulary knowledge were more successful in L2 lexical inferencing than those with weaker depth of vocabulary knowledge. These findings contribute to lexical threshold theories and permit a clearer understanding of earlier findings about the strong role of vocabulary knowledge in L2 inferential success (Haynes \& Baker, 1993; Laufer, 1997; Nassaji, 2004; Nation, 2001; Pulido, 2007). These findings extend earlier research that indicated the important role of learners' level of language proficiency in L2 lexical inferencing ability (Bengeleil \& Paribakht, 2004; Chern, 1993; Fraser, 1999; Haastrup, 1991; Haynes, 1993; Ittzes, 1991; Morrison, 1996). Haastrup and Morrison demonstrated that more linguistically proficient L2 learners could make use of contextual clues more effectively and as a result could make more successful inferences than less proficient learners.

The findings also show that there is no significant difference in this study between EFL learners with varied scores on breadth of vocabulary knowledge and their perceived ease in L2 lexical inferencing; nor is there any significant difference between EFL learners with varied scores on depth of vocabulary knowledge and their perceived ease of inferencing. These findings indicate that for the L2 learners in this study, breadth and depth of vocabulary knowledge had no significant effect on the degree of perceived ease in inferring meanings of unfamiliar words from context. In our study, other factors may have affected learners' perceived ease in inferencing. For example, $\mathrm{Li}$ (1988) reported greater ease in guessing (determined by Likert-scale ratings) when Chinese advanced learners of English processed semantically rich compared with semantically poor sentences. Other factors affecting perceived degree of ease in guessing have been found to be topic familiarity and passage sight vocabulary (Pulido, 2007). In her study, Pulido found that for learners with stronger passage sight vocabularies, the role of passage sight vocabulary in the perception of ease/difficulty in lexical inferencing depended on the degree of familiarity with the topic. Although the group of learners in her study had ample knowledge of the vocabulary in the target passage, this did not compensate for their lack of familiarity with the topic as far as ease of processing was concerned. The findings in our study are also 
consistent with those of Pulido, indicating that for advanced learners with relatively rich lexical knowledge (as in this study), knowledge of vocabulary does not have a significant effect on perceived ease in inferencing, and thus other variables such as topic familiarity may be intervening. Of course, this may not be the case with less proficient learners who have a more limited vocabulary.

Furthermore, the results of this study indicate that although both breadth and depth of vocabulary knowledge contributed significantly to the prediction of L2 lexical inferencing success, breadth of vocabulary knowledge added a noticeable $8 \%$ of explained variance in inferential success over and above the prediction already afforded by depth of vocabulary knowledge. In other words, scores on the VLT made a significant and unique contribution to the prediction of scores on L2 inferential success beyond the prediction provided by scores on the WAT. In comparison, the results of the additional analysis showed that depth of vocabulary knowledge added only an insignificant $0.7 \%$ of explained variance in inferential success over and above the prediction already provided by breadth of vocabulary knowledge. In sum, breadth of vocabulary knowledge is a stronger predictor of L2 lexical inferencing success than depth of vocabulary knowledge. An interesting result arising from our study is that even at higher levels of vocabulary knowledge where most participants have achieved the 10,000 frequency level, size makes a greater difference.

Qian $(1998,1999)$ explored the relative contributions of breadth and depth of vocabulary knowledge to L2 reading comprehension. He found that depth of vocabulary knowledge not only was a better predictor of L2 reading comprehension, but also made a unique contribution to L2 reading comprehension over and above the contribution made by size of vocabulary knowledge. Because in both L1 and L2, inferential success, reading comprehension and vocabulary knowledge are shown to be correlated (Bengeleil \& Paribakht, 2004; Cain, Oakhill, \& Lemmon, 2004; Hafner, 1967; Herman et al., 1987; Nassaji, 2004; Qian, 2005), we expected that our findings would be consistent with those of Qian $(1998,1999)$. However, this was not the case. The inconsistency in the findings may be due to the differences in the participants' demographic and linguistic backgrounds. Whereas the participants in this study were Persian advanced learners of EFL, the participants in Qian's study were Korean and Chinese university-level learners of ESL. Another reason for this inconsistency may be due to the different versions of VLT used for the two studies. Qian used Nation's (1983) version consisting of six test items at each level leading to a total of 90 correct choices; whereas the version that we used in this study was the longer, updated version by Schmitt (2000), consisting of 10 test items at each level, leading to a total of 150 correct choices.

Finally, the analysis shows that success in L2 lexical inferencing and per- 
ceived ease of inferencing are moderately and positively correlated, which means that the more successful inferences EFL learners make, the more ease they perceive, and thus the more enjoyable the task of reading becomes. This finding emphasizes the central role of L2 inferential success in reducing readers' frustration and encouraging their persistence.

Although this study may provide a good indication of the relationship between the two dimensions of vocabulary knowledge-depth and breadth-and EFL learners' ease and success in lexical inferencing, a number of limitations could possibly account for some of the results. Our sample was limited to EFL learners with Persian as their L1. Although using participants with a common L1 makes the results comparable, it can also limit the scope for generalization of the findings. Moreover, this study investigated only one level of proficiency, the advanced level, and so the findings may not be generalizable across a broader range of proficiency. Indeed, learners of all levels encounter unknown words through reading, and the nature of the relationship between vocabulary knowledge and lexical inferencing ease and success may change when those with weaker abilities and lower language proficiency are considered. Finally, the length of the passage and the number of TWs selected for this study were chosen considering time constraints. To increase the generalizability of the findings, lengthier texts with more TWs could be used in future investigations.

\section{Pedagogical Implications}

The findings of this study add to our understanding of factors that contribute to L2 lexical inferencing ability and so may have noteworthy implications for educators. In this study we have empirically established the significance of both breadth and depth of vocabulary knowledge in L2 lexical inferencing success. Language-teachers, materials-writers, and curriculum-designers should, therefore, incorporate both dimensions of vocabulary knowledgebreadth and depth-into L2 curricula. This could be achieved through systematic, long-term vocabulary learning programs that provide opportunities for both intentional and incidental vocabulary learning (Schmitt, 2008). The intentional learning of vocabulary (i.e., when the purpose is specifically to learn vocabulary through an explicit focus) is of great significance (Laufer, 2005), because it is the best means for establishing the first step in learning a lexical item, that is, the form-meaning link. Once this initial link is established, the incidental learning of vocabulary should then be promoted through extensive exposure to reading and listening (Schmitt). By enabling learners to encounter words many times and in varying contexts, extensive exposure can help them to acquire not only new lexical items (Horst, 2005), but also various aspects of word knowledge for each lexical item (Webb, 2007). Graded readers and for more advanced learners, authentic texts are recommended for this purpose (Schmitt, 2008). 
Another implication is centered in the finding that breadth is more influential than depth of vocabulary knowledge in success in L2 lexical inferencing. Therefore, this dimension of vocabulary knowledge may require more serious attention when one is designing L2 syllabi and activities. In fact, studies have shown that the vocabulary size of university entry-level EFL learners is on average 2,100 word families (Laufer, 2000), which is not even close to the reported size requirements for reading a wide variety of texts (i.e., 8,0009,000 word families). Possibly, to overcome such an overwhelming vocabulary learning challenge, "students need the willingness to be active learners over a long period of time, for without this, they are unlikely to achieve any substantial vocabulary size, regardless of the quality of instruction" (Schmitt, 2008, p. 333). Language-teachers can play an essential role in this regard by encouraging learners and requiring them to learn new lexical items and providing guidance on which words to learn and which learning strategies to use. For this purpose, frequency lists and teacher-friendly research findings could provide useful support to teachers.

Our study also showed that inferential success and perceived ease of inferencing are positively correlated. Therefore, training language-learners in lexical inferencing techniques and giving them opportunities to practice inferencing from context could be one way to make reading an easier, more enjoyable task. Several researchers have proposed techniques and strategies for dealing with unknown words in texts (Clarke \& Nation, 1980). Studies have shown that such formal training can have positive effects on inferential success and reading comprehension (Walters, 2004, 2006), so is worth the time and effort in the language classroom.

\section{Suggestions for Further Research}

Earlier studies showed that an important factor that affects success in lexical inferencing is learners' language proficiency. This study focused on vocabulary knowledge as only one aspect of linguistic knowledge. Future research could explore the relationships between other dimensions of language proficiency and inferential success, for example, the role of grammatical knowledge in L2 lexical inferencing. Moreover, considering the important role that lexical inferencing plays in incidental vocabulary learning, future investigations could consider the relationship between knowledge of vocabulary (breadth vs. depth) and the subsequent acquisition and retention of inferred words. These are important problems to consider for SLA research on the nature of L2 lexical inferencing, its processing, and its outcomes.

\section{The Authors}

Sarvenaz Hatami is a doctoral student in the TESL program at the University of Alberta. Her research interests include second-language vocabulary-learning, pragmatic development, and individual differences in second-language acquisition. 
Mansoor Tavakoli is associate professor in TEFL at the University of Isfahan, Iran, where he has been teaching TEFL courses for over 15 years. His research interests are second-language acquisition, language-teaching, and assessment. He has published over 50 scientific research articles in local and international journals.

\section{References}

Ames, W.S. (1966). The development of a classification scheme of contextual aids. Reading Research Quarterly, 2(1), 57-82.

Bengeleil, N.F., \& Paribakht, T.S. (2004). L2 reading proficiency and lexical inferencing by university EFL learners. Canadian Modern Language Review, 61, 225-249.

Brown, C. (1993). Factors affecting the acquisition of vocabulary: Frequency and saliency of words. In T. Huckin, M. Haynes, \& J. Coady (Eds.), Second language reading and vocabulary learning (pp. 263-286). Norwood, NJ: Ablex.

Cain, K., Oakhill, J., \& Lemmon, K. (2004). Individual differences in the inference of word meanings from context: The influence of reading comprehension, vocabulary knowledge, and memory capacity. Journal of Educational Psychology, 96, 671-681.

Carton, A. (1971). Inferencing: A process in using and learning language. In P. Pimsleur \& T. Quinn (Eds.), The psychology of second language learning (pp. 45-58). Cambridge, UK: Cambridge University Press.

Chern, C. (1993). Chinese students' word-solving strategies in reading in English. In T. Huckin, M. Haynes, \& J. Coady (Eds.), Second language reading and vocabulary learning (pp. 67-82). Norwood, NJ: Ablex.

Clarke, D.F., \& Nation, I.S.P. (1980). Guessing the meanings of words from context: Strategy and techniques. System, 8, 211-220.

Dubin, F., \& Olshtain, E. (1993). Predicting word meanings from contextual clues: Evidence from L1 readers. In T. Huckin, M. Haynes, \& J. Coady (Eds.), Second language reading and vocabulary learning (pp.181-202). Norwood, NJ: Ablex.

Ellis, R. (1994). Factors in the incidental acquisition of second language vocabulary from oral input: A review essay. Applied Language Learning, 5(1), 1-32.

Frantzen, D. (2003). Factors affecting how second language Spanish students derive meaning rom context. Modern Language Journal, 87, 168-199.

Fraser, C. (1999). Lexical processing strategy use and vocabulary learning through reading. Studies in Second Language Acquisition, 21, 225-241.

Haastrup, K. (1989). The learner as word processor. AILA Review, 6, 34-46.

Haastrup, K. (1991). Lexical inferencing procedures or talking about words: Receptive procedures in foreign language learning with special reference to English. Tubingen, Germany: Gunter Narr.

Hafner, L.E. (1967). Using context to determine meanings in high school and college. Journal of Reading, 10, 491-498.

Haynes, M. (1993). Patterns and perils of guessing in second language reading. In T. Huckin, M. Haynes, \& J. Coady (Eds.), Second language reading and vocabulary learning (pp. 46-64). Norwood, NJ: Ablex.

Haynes, M., \& Baker, I. (1993). American and Chinese readers learning from lexical familiarizations in English text. In T. Huckin, M. Haynes, \& J. Coady (Eds.), Second language reading and vocabulary learning (pp. 130-150). Norwood, NJ: Ablex.

Herman, P.A., Anderson, R.C., Pearson, P.D., \& Nagy, W.E. (1987). Incidental acquisition of word meaning from expositions with varied text features. Reading Research Quarterly, 22, 263-284.

Horst, M. (2005). Learning L2 vocabulary through extensive reading: A measurement study. Canadian Modern Language Review, 61, 355-382.

$\mathrm{Hu}, \mathrm{M} .$, \& Nation, I.S.P. (2000). Unknown vocabulary density and reading comprehension. Reading in a Foreign Language, 13, 403-430. 
Ittzes, K. (1991). Lexical guessing in isolation and context. Journal of Reading, 34, 360-366.

Laufer, B. (1997). The lexical plight in second language reading: Words you don't know, words you think you know, and words you can't guess. In J. Coady \& T. Huckin (Eds.), Second language vocabulary acquisition: A rationale for pedagogy (pp. 20-34). New York: Cambridge University Press.

Laufer, B. (2000). Task effect on instructed vocabulary learning: The hypothesis of "involvement." Selected Papers from AILA '99 Tokyo (pp. 47-62). Tokyo: Waseda University Press.

Laufer, B. (2005). Focus on form in second language vocabulary acquisition. In S.H. FosterCohen, M.P. Garcia Mayo, \& J. Cenoz (Eds.), EUROSLA Yearbook 5 (pp. 223-250). Amsterdam: John Benjamins.

Laufer, B., Elder, C., Hill, K., \& Congdon, P. (2004). Size and strength: Do we need both to measure vocabulary knowledge? Language Testing, 21, 202-226.

Laufer, B., \& Paribakht, T.S. (1998). The relationship between passive and active vocabularies: Effects of language learning context. Language Learning, 48, 365-391.

$\mathrm{Li}, \mathrm{X}$. (1988). Effects of contextual cues on inferring and remembering meanings of new words. Applied Linguistics, 9, 402-413.

Morrison, L. (1996). Talking about words: A study of French as a second language learners' lexical inferencing procedures. Canadian Modern Language Review, 53, 41-75.

Nassaji, H. (2003). L2 vocabulary learning from context: Strategies, knowledge sources, and their relationship with success in L2 lexical inferencing. TESOL Quarterly, 37, 645-670.

Nassaji, H. (2004). The relationship between depth of vocabulary knowledge and L2 learners' lexical inferencing strategy use and success. Canadian Modern Language Review, 61, 107-134.

Nation, I.S.P. (1983). Testing and teaching vocabulary. Guidelines, 5(1), 12-25.

Nation, I.S.P. (2001). Learning vocabulary in another language. Cambridge, UK: Cambridge University Press.

Nation, I.S.P. (2006). How large a vocabulary is needed for reading and listening? Canadian Modern Language Review, 63, 59-82.

Nurweni, A., \& Read, J. (1999). The English vocabulary knowledge of Indonesian university students. English for Specific Purposes, 18, 161-175.

Paribakht, T.S. (2005). The influence of first language lexicalization on second language lexical inferencing: A study of Farsi-speaking learners of English as a foreign language. Language Learning, 55, 701-748.

Paribakht, T.S., \& Wesche, M. (1999). Reading and "incidental" L2 vocabulary acquisition: An introspective study of lexical inferencing. Studies in Second Language Acquisition, 21, 195224.

Pulido, D. (2007). The effects of topic familiarity and passage sight vocabulary on L2 lexical inferencing and retention through reading. Applied Linguistics, 28, 66-86.

Qian, D.D. (1998). Depth of vocabulary knowledge: Assessing its role in adults' reading comprehension in English as a second language. Unpublished doctoral dissertation, University of Toronto.

Qian, D.D. (1999). Assessing the roles of depth and breadth of vocabulary knowledge in reading comprehension. Canadian Modern Language Review, 56, 282-308.

Qian, D.D. (2005). Demystifying lexical inferencing: The role of aspects of vocabulary knowledge. TESL Canada Journal, 22, 34-54.

Read, J. (1988). Measuring the vocabulary knowledge of second language learners. RELC Journal, 19(2), 12-25.

Read, J. (1993). The development of a new measure of L2 vocabulary knowledge. Language Testing, 10, 355-371.

Read, J. (1998). Validating a test to measure depth of vocabulary knowledge. In A.J. Kunnan (Ed.), Validation in language assessment (pp. 41-60). Mahwah, NJ: Erlbaum. 
Read, J. (2000). Assessing vocabulary. Cambridge, UK: Cambridge University Press.

Read, J. (2004). Plumbing the depths: How should the construct of vocabulary knowledge be defined? In P. Bogaards \& B. Laufer (Eds.), Vocabulary in a second language: Selection, acquisition, and testing (pp. 209-227). Amsterdam: John Benjamins.

Schmitt, N. (2000). Vocabulary in language teaching. Cambridge, UK: Cambridge University Press.

Schmitt, N. (2008). Review article: Instructed second language vocabulary learning. Language Teaching Research, 12, 329-363

Schmitt, N., Schmitt, D., \& Clapham, C. (2001). Developing and exploring the behavior of two new versions of the Vocabulary Levels Test. Language Testing, 18(1), 55-88.

Schouten-van Parreren, C. (1989). Vocabulary learning through reading: Which conditions should be met when presenting words in texts? AILA Review, 6, 75-85.

Smith, M.L., \& Glass, G.V. (1987). Research and evaluation in education and social sciences. Englewood Cliffs, NJ: Prentice-Hall.

Sternberg, R.J. (1987). Most vocabulary is learned from context. In M.G. McKeown \& M.E. Curtis (Eds.), The nature of vocabulary acquisition (pp. 89-105). Hillsdale, NJ: Erlbaum.

Vermeer, A. (2001). Breadth and depth of vocabulary in relation to L1/L2 acquisition and frequency of input. Applied Psycholinguistics, 22, 217- 234.

Walters, J. (2004). Teaching the use of context to infer meaning: A longitudinal survey of L1 and L2 vocabulary research. Language Teaching, 37, 243-252.

Walters, J. (2006). Methods of teaching inferred meaning from context. RELC Journal, 37(2), 176-190.

Webb, S. (2007). The effects of repetition on vocabulary knowledge. Applied Linguistics, 28(1), 46-65.

Wesche, M., \& Paribakht, T.S. (1996). Assessing second language vocabulary knowledge:

Depth versus breadth. Canadian Modern Language Review, 53, 13-40.

Wilkins, D.A. (1972). Linguistics in language teaching. London: Edward Arnold. 


\section{Appendix}

\section{Passage and Target Words}

How Man Began

Starting with pieces of a Neanderthal skeleton accidentally unearthed in Germany in 1856, archaeologists have sweated over excavations in Africa, Europe, Australia and Asia. They have been trying to find fossil evidence that will answer the most fundamental questions of our existence: when, where and how did the human race arise?

Recent research is raising some staggering possibilities and calling into question many of the long-held textbook views on the genesis of man. Indeed, the longer scientists study the fossil record, the more convinced they become that evolution did not make a simple transition from ape to human.

The story of that survivor, who came to dominate the earth, begins in Africa's verdant forests some four million years ago. This is where the oldest hominid fossils have been uncovered. A crucial discovery came in 1974, when an expedition to Ethiopia, led by American anthropologist Donald Johanson, painstakingly pieced together a remarkable ancient primate skeleton, classified Australopithecus.

Unlike any species of primate known to have come before, researchers could tell that this "link" between apes and humans walked fully upright. These short creatures (males were 150 centimeters tall) were probably only slightly more intelligent than the average ape. Their upright stance and bipedal locomotion, however, may have given them an advantage by freeing their hands, making them more efficient food gatherers.

Australopithecus thrived and passed their genes on to future generations, giving rise to a species called Homo habilis, or "handy man." Appearing perhaps more than two million years ago, the new hominid probably didn't look terribly different from its predecessors. It only had a somewhat larger brain, and worked out for the first time how to make stone tools.

Homo habilis later evolved into a taller, stronger, cleverer variety of human, Homo erectus. This variety was probably almost indistinguishable from modern humans from the neck down. Fossils from this extraordinarily successful and mobile species were first found thousands of kilometers away from its original home in Africa.

The oldest confirmed fossils from modern humans, Stringer points out, are from Africa and the Middle East, up to 120,000 years ago. The first modern Europeans and Asians don't show up until tens of thousands of years after that.

But what about the new report of the 200,000-year-old Homo sapiens cranium in China? It is getting only a cautious reception from most scientists, in part because the dating technique used is still experimental. 
Stringer thinks the claim that the skull is related to modern humans won't stand up to close scrutiny. The only certainty in this endlessly fascinating field is that there are copious surprises left to come. 